PALESTRA

\title{
ESCOLA DE ENFERMAGEM DA UNIVERSIDADE FEDERAL DA BAHIA - 40 ANOS DE HISTÓRIA -
}

\author{
Josicélia Dumêt Fernandes 1
}

Através do Decreto Lei no 8.779 de 22 de janeiro de 1946, foi criada a Escola de Enfermagem da Universidade Federal da Bahia nos termos do Parágrafo 20 do Artigo 20 do Estatuto de 02 de julho de 1946 dessa mesma instituição. Entrou em funcionamento em março do ano seguinte, utilizando-se de instalações da Faculdade de Medicina, no Terreiro de Jesus, durante os dois primeiros anos de vida, passando depois a funcionar no prédio do então Hospital das Clínicas, mudando-se, em dezembro de 1950, para suas instalações definitivas.

A capacitação docente foi uma preocupação que emergiu desde o início do funcionamento da Escola. Essa preocupação também foi estendida para o desenvolvimento do ensino, bem como para a problemática da profissão, externando o desejo de aperfeiçoamento em diversos aspectos. Vários foram os estudos feitos sobre a formação do enfermeiro, suas carências, delimitações e mudanças curriculares.

Com as medidas legais de caráter administrativo que foram operacionalizados no País, na segunda metade da década de 60 , surge a Lei 5.540 de 28 de novembro de 1968 - Lei da Reforma Universitária. Através desta Lei, o Estado procura diminuir as pressões sobre o aparelho universitário, respondendo às reivindicações estudantis sobre maior oportunidade de acesso a esse órgão formado, através da ampliação do número de vagas e absorção do máximo de candidatos.

A EEUFBa., como integrante do aparelho universitário, segue as determinações dessa Lei e tem ampliado o seu número de alunos.

Se, em 1947, a EEUFBa., contava, no seu quadro, com 07 alunos, em 1986, conta com 418 alunos.

De 1950 (ano em que se formou a primeira turma de enfermeiros) até 1986, a EEUFBa., diplomou 1.306 bacharéis em enfermagem, 181 especialistas e 12 mestres.

Em 1968 (ano de criação da Lei da Reforma Universitária), havia 38 professores para 197 alunos matriculados. Isto significa dizer que havia um professsor para 5,1 alunos. Já em 1986, existem 54 professores para 418 alunos matriculados (na graduação e pós-graduação), ou seja, um professor para 7,7 alunos. Houve, portanto, um crescimento de $112,1 \%$ no número de alunos, enquanto que o número de professores foi acrescido em apenas $42,1 \%$.

Em relação ao número de funcionários, a EEUFBa. contava, em 1968, no seu quadro técnico- administrativo, com 54 servidores. Já, em 1986, esse número está reduzido em 45 .

Esse crescimento desproporcional entre o número de alunos versus número de professores e funcionários é perfeitamente compreensível dentro das determinações da Lei da Reforma Universitária que, em síntese, estão dirigidas para a formação do maior número de profissionais através da utilização racional dos recursos existentes (maior produtividade). Logo, amplia-se o número de vagas/alunos, sem, contudo, haver ampliação no quadro de docentes e de técnicoadministrativos.

A medida encontrada, pela EEUFBa., para compatibilizar essa distorção existente na relação desproporcional entre número de docentes e número de alunos, foi a retirada gradativa das professoras que ocupavam cargos de chefia de unidades do hospital universitário. Assim é que, a partir de 1977, a relação de integração entre a EEUFBa. e o Hospital Professor Edgard Santos fica reduzida à chefia da divisão e 50\% das coordenações dos serviços de enfermagem desse hospital.

Por outro lado, as medidas adotadas pela Lei 5.540 atendem, também, às exigências de trabalho que, baseado na sofisticação tecnológica do desenvolvimento industrial, requer um número crescente de profissionais qualificados. Nessa perspectiva, foi criado, na EEUFBa., em 1973, o curso de Especialização em Enfermagem Médico-Cinúrgica sob a forma de residência.

A expansão da of erta de vagas, por sua vez, vem exigir maior formação do corpo docente, respondendo às necessidades de especialização para atender à áre a tecnológica e a uma demanda maior do processo produtivo. Destarte, a EEUFBa. cria o Curso de Mestrado em Enfermagem que, aprovado pela Câmara de Pós-Graduação em 06 de novembro de 1978, entrou em funcionamento no ano seguinte, juntamente com o Curso de Especialização em Enfermagem MédicoCirúrgica, já existente, e, em 1980, com mais uma área do Curso de Especialização em Enfermagem Comunitária.

A EEUFBa., portanto, tomando como ponto de partida a qualificação do seu pessoal docente, procura proporcionar facilidades para o preparo dos professores que estavam em condições de prestar concurso para Livre-Docência. Como resultado dessa iniciativa, a EEUFBa. passa a contar, em 1977, com 05 professores qualificados como Livre-Docentes e um

1. Prof. Adjunto da Escola de Enfermagem da UFBa. 
Doutor. Ademais, se em 1979 contava-se com 04 Mestres, em 1986, passa-se a contar com 18 além de 10 com mestrado em andamento.

A Reforma Universitária traz, portanto, como corolário, o aumento da produção científica através dos cursos de pós-graduação com seus trabalhos de conclusão, da obrigatoriedade para qualificação de docentes e, finalmente, dos incentivos legais da carreira do magistério. Assim é que, apesar do número insuficiente de professores, a produção científica da EEUFBa. cresceu sensivelmente. Se, em 1977, ela contava com 55 trabalhos científicos, em 1986, esse número passou para 169 , sendo que $30,7 \%$ desse total correspondem a trabalhos concluídos no biênio 84/85. Este fato deve-se, também, à criação da Comissão Interna de Apoio à Produção Científica, bem como à reativação da publicação da Revista Baiana de Enfermagem.

Observa-se ainda um crescimento vertiginoso em relação aos trabalhos de extensão, a qual, rompendo os muros da instituição, estendem-se através de programas interinstitucionais como é o caso do subprojeto de ensino e saúde na cidade de Cachoeira, Programa Integrado de Saúde Rural de Cruz das Almas, Programa de Desenvolvimento Integrado de Sapeaçu, Ações Integradas de Saúde, Programa de Apoio Pedagógico aos Profissionais de Saúde, Projeto Semi-Árido e ainda Programa e Ações de Enfermagem no Campus Avançado de Barreiras, dentre outros.

Ainda em relação às atividades de extensão, a EEUFBa. criou, em 1985, um Núcleo de Extensão como forma de incentivar e agilitar os serviços estendidos à comunidade.

Diante desse quadro, observa-se que a partir da Lei da Reforma Universitária foram ampliados não só o número de alunos mas também as atividades de pesquisa e extensão, sem a respectiva correspondência na ampliação do quadro docente e técnico-administrativo. Acresce-se a isto o fato das verbas destinadas ao ensino superior, através do Ministério de Educação, tornarem-se cada vez mais insuficientes.

Toda essa situação tem sua origem na segunda metade da década de 60 , quando começa a desenvolver-se a ideologia do "desenvolvimento". O País necessitava alcançar um certo grau de desenvolvimento a fim de legitimar o modelo econômico adotado em 1964. Passa, então, a prevalecer a idéia de que, para haver desenvolvimento, é necessário crescimento econômico. Ora, se desenvolvimento significava crescimento econômico, Educação e Saúde passaram a ser definidas como áreas secundárias pelo planejamento estatal. Começa, então, uma tendência, por parte do Estado, em se desobrigar com a Educação e Saúde da população.

Com o acirramento das contradições da sociedade brasileira, evidenciadas a partir de 1964, observa-se, a partir da segunda metade da década de 70 , uma intensa mobilização da população no sentido de alcançar o fortalecimento da sociedade civil e redemo- cratização dos aparelhos estatais com vistas ao reordenamento das relações políticas e sociais, em busca de uma sociedade mais justa, mais igualitária e, sobretudo, mais brasileira. Inicia-se, a partir de então, um amplo movimento de denúncias às distorções operadas na assistência à saúde da população e na qualidade do ensino. Em resposta a essas pressões, o Estado redefine suas políticas sociais

Nesses termos, o Ministério de Educação e Cultura, Ministério da Saúde e Ministério da Previdência e Assistência Social, consubstanciados nos planos governamentais, passam a estudar os problemas da formação e utilização de recursos humanos na área da saúde, a fim de propor diretrizes para as sanções que permitam a correção das principais distorções que vinham sendo apontadas.

Dentro das medidas recomendadas pelos órgãos estatais, a EEUFBa inicia a revisão do seu currículo de graduação. Assim é que, em 1980, é implantado um novo currículo que leva em conta os novos enfoque das práticas de saúde.

Em decorrência das mudanças galopantes que se processam na sociedade, a EEUFBa, em 1983, sente a necessidade de uma avaliação do currículo adotado. Para tal fim, foi criada uma comissão composta por professores e alunos e que vem desenvolvendo um processo de avaliação contínua do currículo do curso de graduação. Em relação ao curso de pós-graduação já foi feita, em 1985 , a avaliação do Curso de Mestrado e, em 1986, do curso de Especialização, visando à reformulação dos mesmos.

Como se pode observar, pelo exposto, todo esse desenvolvimento e todos os esforços constantes de professores, estudantes e funcionários, não se dão de forma isolada da sociedade. A EEUFBa., a despeito das particularidades historicamente determinadas e das características próprias que definem sua especificidade, é, indiscutivelmente, parte das questões gerais da sociedade. Está, portanto, submetida aos mesmos determinantes estruturais e conjunturais das políticas sociais e, mais especificamente, dos setores Educação e Saúde.

Hoje, ao lado da crise da universidade, e mais amplamente da crise da sociedade brasileira, a EEUFBa. se retempera, procurando dinamizar o seu funcionamento, pautando-se nas diretrizes de uma gestão democrática. Contudo, o processo democrático, por suas próprias características, propõe reflexões mais amplas e mais demoradas, o que, de certa forma, causa um prolongamento no tempo para a geração de seus frutos.

A EEUFBa não tem, nem poderia ter, a capacidade para, sozinha, acionar propulsivamente o desenvolvimento sócioeconômico da sociedade. Cabe-lhe, porém, a responsabilidade de preparar indivíduos que, no desempenho de suas atividades profissionais, possam assumir a vanguarda das transformações progressistas no sentido de garantir Educação e Saúde como direito de todos e dever do Estado. 